\title{
Phylogeography of a nematode (Heligmosomoides polygyrus) in the western Palearctic region: persistence of northern cryptic populations during ice ages?
}

\author{
C. NIEBERDING,${ }^{*}+$ R. LIBOIS,${ }^{*}$ C. J. DOUADY $₫$ S. MORAND + and J. R. MICHAUX*十 \\ *Unité de Recherches Zoogéographiques, Institut de Zoologie, Quai Van Beneden, 22, 4020 Liège, Belgium, +Centre de Biologie et de \\ Gestion des Populations, Campus international Agropolis de Baillarguet CS 30016, 34988 Montferrier-sur-Lez, France, $\ddagger$ Equipe \\ Hydrobiologie et Ecologie Souterraines et Plateforme d'Ecologie Moléculaire, UMR 5023 - Ecologie des Hydrosystèmes Fluviaux, Bât. \\ Forel (403) - La Doua, Université Lyon I, 43 Bd du 11-11-1918, 69622 Villeurbanne cedex, France
}

\begin{abstract}
This study establishes the continental phylogeographical pattern of a European nematode, Heligmosomoides polygyrus (Dujardin, 1845; Heligmosomoidea). We sequenced 687 base pairs of the mitochondrial DNA (mtDNA) cyt $b$ gene for 136 individuals collected in 22 localities. The results revealed that $H$. polygyrus populations are separated into five major units corresponding to the Italian, northern European (Denmark and Ireland), Iberian, western European, and Balkan populations. Different subclades were also observed within the first two groups. Based on the rate of molecular evolution of $H$. polygyrus cyt $b$ gene-estimated to $3.5 \%-3.7 \%$ divergence per million years $(\mathrm{Myr})$ in a previous study - the isolation time of the five clades was estimated between $2.5 \pm 0.24$ and $1.5 \pm 0.23$ million years ago. Moreover, $H$. polygyrus presents a higher genetic variability in the Mediterranean peninsulas as compared to northwestern Europe, highlighting the role of these regions as refuge areas. Like its specific host, the wood mouse Apodemus sylvaticus, $H$. polygyrus' pattern of postglacial recolonization of northwestern Europe was initiated from Iberian populations, while Italian and Balkan populations did not expand to the north. The results also suggest the existence of forested and temperate refuges in the southern British Isles during the Quaternary. Finally, the genetic diversity as well as the level of genetic divergence between the lineages of $\mathrm{H}$. polygyrus are compared to those observed in other vertebrate and invertebrate phylogeographical studies: the existence of highly differentiated lineages in $\mathrm{H}$. polygyrus (5\%-10\% of genetic divergence) highlights that the effects of Pleistocene climate changes on free-living organisms are also reflected in their obligate parasites.
\end{abstract}

Keywords: cryptic refuge, Heligmosomoidea, mitochondrial cyt $b$ gene, nematode, parasite, western Palearctic region

Received 27 July 2004; revision received 29 October 2004; accepted 29 November 2004

\section{Introduction}

Phylogeography is a field of research which studies the principles and processes determining the geographical distribution of genetic lineages. It is useful in understanding processes such as population subdivision, speciation and ecological adaptation to past climatic changes (Avise 2000).

Correspondence: Caroline Nieberding, Fax: +32 436659 45;

E-mail: caroline.nieberding@ulg.ac.be
The number of phylogeographical studies on animals increased greatly during recent years, particularly in Europe, but are mainly concerned with vertebrate taxa (fishes, amphibians, birds and mammals) (Taberlet et al. 1998; Hewitt 1999; Avise 2000), while invertebrate taxa, particularly parasite species, still remain understudied (but see Brown et al. 1997; Burban et al. 1999; Attwood 2001; Wickström et al. 2003). However, the number of existing parasite species is estimated to several hundreds of thousands and they represent c. $30 \%$ of the eukaryote species biodiversity (De Meeûs \& Renaud 2003); parasites might display completely original 
phylogeographical patterns, considering their host-dependent dispersal abilities. Particularly, the traditional biogeographical model of temperate species in Europe predicts that temperateadapted species survived the glacial periods of the Pleistocene in refuge areas located in the southern European peninsulas of Iberia, Italy and the Balkan or in Eastern regions (Bilton et al. 1998), without any mention of more northern refuge regions. More precisely, the current flora and fauna of the British Isles are generally believed to consist exclusively of postglacial colonists from southern refuges (Taberlet et al. 1998; Hewitt 2000). However, an increasing number of studies propose the presence of a disjoint and cryptic (i.e. not detected in vertebrates' fossil records) refuge in the southern part of the British Isles or on a land area formed by the exposed bed of the southern North Sea existing during the glacial maxima (Stewart \& Lister 2001; Hänfling et al. 2002; Tzedakis 2003). The phylogeographical study of invertebrate and parasite taxa, whom dispersal abilities are more variable than vertebrates', may highlight particular schemes of survival and recolonization during Quaternary ice ages in Europe.

To our knowledge, very few studies investigated the phylogeographical history of an animal parasite species that take into account the phylogeographical history of its host(s): Burban et al. (1999) and Burban \& Petit (2003) showed that the bast scale Matsucoccus feytaudi and its specific host, the maritime pine Pinus pinaster, display only partially congruent patterns in western Europe and northern Africa, likely because some of the pine stands were planted by humans, which disturbs the pine ancestral phylogeographical signal. Pellmyr et al. (1998) showed that the presence of Bowlesia incana (Apiaceae) in North America was far older than was previously proposed by assessing the phylogeographical history of its host-specific herbivore Greya powelli (Lepidoptera). Campbell et al. (2000) showed that the surprisingly rapid spread of Schistosoma mansoni in North and South America during the African slave trade was explained by the Neotropical origin of the parasite's main intermediate host in Africa, Biomphalaria glabrata. Wickström et al. (2003) revealed a complex phylogeographical history of the circumpolar Paranoplocephala arctica species complex (Cestodes) parasitizing collared lemmings (Dicrostonyx spp.) in the Holarctic region. Eventually, the main issue of these studies highlighted that parasites can be used as host evolutionary print and 'biological magnifying glass' in specifying their hosts' phylogeographical history.

At the population level, several studies put into light hosts and parasites life history traits responsible of the population genetic structure observed in helminth parasites (Anderson et al. 1998). These studies showed that the degree of genetic differentiation among parasite populations depends on gene flow, which is generally determined by host mobility, effective (i.e. breeding) population sizes $\left(N_{e}\right)$, which is determining the rate of genetic drift and therefore the rate of independent differentiation of populations, and reproductive mode (Blouin et al. 1995; Nadler 1995). $N_{e}$ and reproductive mode of parasite species may also determine within-population diversities (Nadler 1990, 1995; Blouin et al. 1999). Most helminths studied to date are parasites of humans, domestic animals, commensals or game species. They present high genetic diversity within populations, but extremely low differentiation among localities, highlighting high levels of gene flow linking allopatric populations (Mulvey et al. 1991; Blouin et al. 1992; Blouin et al. 1999; Hawdon et al. 2001). However, this pattern of population structure may not be retrieved in wild, nonhuman and natural host-associated helminth species (Nadler 1995; Dybdahl \& Lively 1996; Anderson et al. 1998). For example, Mazamastrongylus odocoilei on deer presents substantial population subdivision and isolation by distance, in accordance with limited host movement. Within-population diversities of $M$. odocoilei are high, likely because of large $N_{e}$ (Blouin et al. 1995). Finally, Heterorhabditis marelatus is a parasite of soil-dwelling insects: low mtDNA diversity within populations and strong subdivided population structure are observed because of small $N_{e}$ and restricted gene flow (Blouin et al. 1999). But none of these studies took into account historical factors, like Pleistocene climatic changes, to explain the current pattern of genetic variability. However, deep genetic differentiation among conspecific populations should involve larger spatial and temporal processes than those considered in population genetics.

In this context, a large phylogeographical study performed on parasites like nematodes would enable to understand whether and how Pleistocene climatic fluctuations may have affected the genetic structure of parasite species. For this purpose, we studied the phylogeographical pattern of the nematode Heligmosomoides polygyrus (Heligmosomoidea), a direct (without intermediate host) and specific endoparasite of the wood mouse Apodemus sylvaticus (Muridae, Rodentia). A. sylvaticus is a forest dweller present throughout Europe since at least 3 Myr (Michaux \& Pasquier 1974). The host and its parasite are common and geographically widespread in the western Palearctic region. Therefore, both species probably survived the Quaternary glaciations through important fluctuations in their distribution range (Michaux et al. 2003; Nieberding et al. 2004). H. polygyrus exclusively reproduces sexually. Its first larval stages are free and require 4-6 days to become infective. Host contamination occurs after ingestion of parasitized faeces; adult parasites live in the intestine and produce eggs in the host faeces about 9 days after ingestion and will continue to do so during the next 9 months (Ehrenford 1954). Individuals in the free-living stage have virtually no dispersal abilities, so we expect that gene flow in this species is determined primarily by host movement. Moreover, $H$. polygyrus' high prevalence and abundance determine high $N_{e}$ (Goüy de 
Bellocq et al. 2003). We may therefore expect high withinpopulation diversities.

In a previous study (Nieberding et al. 2004), the spatial and temporal congruences of the phylogeographical patterns between $H$. polygyrus and A. sylvaticus were analysed over the southwestern continental Palearctic region, and the relative rate of molecular evolution of the cytochrome $b$ (cyt b) gene in both species was compared. The aims of the present study are: (i) to extend the analysis of H. polygyrus' phylogeographical pattern to the northern part of its distribution range; and (ii) to discuss the particularities of $H$. polygyrus' phylogeographical pattern in comparison with those of other vertebrate and invertebrate taxa, in the light of the knowledge on population genetic structure and diversity of nematode parasite species.

\section{Materials and methods}

\section{Samples collection and sequencing}

A total of 136 adult Heligmosomoides polygyrus from 22 localities spread over its whole continental distribution range were analysed (Table 1, Fig. 1). All samples were identified at the species level. Tissues are held in the collection of Michaux J. and Nieberding C. housed at the 'Centre de Biologie et de Gestion des Populations' (Montpellier, France).

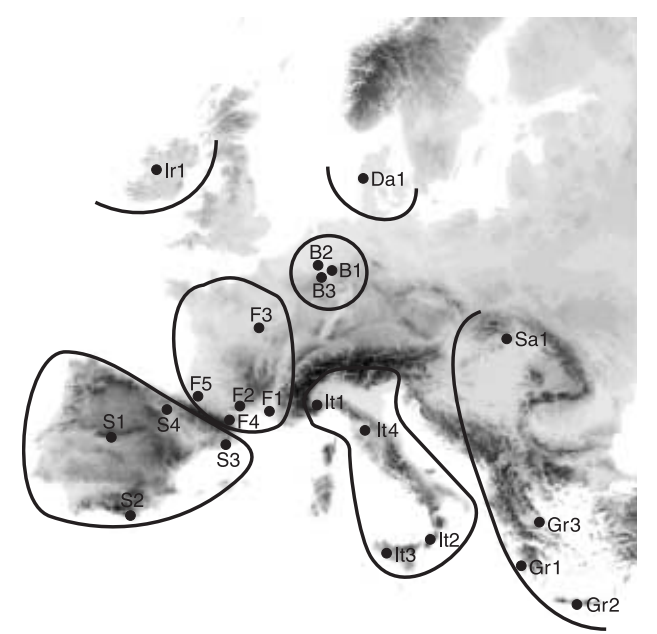

Fig. 1 Geographic distribution of Heligmosomoides polygyrus samples. The zone corresponds to the distribution range of its specific host, Apodemus sylvaticus. The main European biogeographical barriers are represented: the Pyrenees in the west, the Alps in the centre and the Carpathian in the east. The bold lines indicate the subdivision of populations in seven geographical groups in AMOvA(see Table 2).

DNA from $H$. polygyrus individuals was extracted as reported by Goüy de Bellocq et al. (2001). Six hundred eighty-seven (687) bp of cyt $b$ gene were amplified by the polymerase chain reaction (PCR) specific primers $1 \mathrm{~F}$

Table 1 Geographic distribution and references of Heligmosomoides polygyrus individuals used for the experiments

\begin{tabular}{|c|c|c|c|c|c|}
\hline \multicolumn{2}{|c|}{ Geographic origin } & \multirow{2}{*}{$\begin{array}{l}\text { Samples symbols } \\
\text { (see Fig. 1) }\end{array}$} & \multirow{2}{*}{$\begin{array}{l}\text { Number of } \\
\text { H. polygyrus }\end{array}$} & \multirow[b]{2}{*}{ Tissue samples } & \multirow{2}{*}{$\begin{array}{l}\text { EMBL Accession } \\
\text { nos }\end{array}$} \\
\hline Country & Region & & & & \\
\hline \multirow[t]{3}{*}{ Belgium } & Liège & B1 & 11 & CN 894-3-908-1 & AJ608854-AJ608862 \\
\hline & Hainaut & B2 & 6 & CN 1006-2-1009-1 & AJ608863-AJ608868 \\
\hline & Luxembourg & B3 & 2 & CN 1183-1-1183-2 & AJ608869-AJ608870 \\
\hline Denmark & Varde & Da1 & 8 & CN 1200-1-1209-2 & AJ630628-AJ630635 \\
\hline \multirow[t]{5}{*}{ France } & Hérault & $\mathrm{F} 1$ & 6 & CN 980-1-987-1 & AJ608829-AJ608833 \\
\hline & $\begin{array}{l}\text { Pyrénées orientales } \\
\text { (Banyuls/mer) }\end{array}$ & $\mathrm{F} 2$ & 9 & CN 968-1-969-5 & AJ608834-AJ608840 \\
\hline & Loiret & F3 & 6 & CN 1013-1-1019-1 & AJ608847-AJ608853 \\
\hline & $\begin{array}{l}\text { Pyrénées orientales } \\
\text { (Py Mantet) }\end{array}$ & $\mathrm{F} 4$ & 6 & CN 1139-1-1144-1 & AJ608841-AJ608846 \\
\hline & Pyrénées atlantiques & F5 & 2 & CN 1295-1, 1295-6 & AJ630643-AJ630644 \\
\hline \multirow[t]{3}{*}{ Greece } & Peloponnisos & Gr1 & 2 & CN 1246-1-1246-3 & AJ608916-AJ608917 \\
\hline & Crete & Gr2 & 6 & CN 1197-2-1218-1 & AJ608909-AJ608914 \\
\hline & Thessalia & Gr3 & 1 & CN 1221-1 & AJ608915 \\
\hline Ireland & County Down & Ir1 & 7 & CN 1187-1-1198-2 & AJ630636-AJ630642 \\
\hline \multirow[t]{4}{*}{ Italy } & Liguria & It1 & 13 & CN 988-1-996-1 & AJ608890-AJ608902 \\
\hline & Calabria & It2 & 5 & CN 839-1-867-1 & AJ608884-AJ608889 \\
\hline & Sicilia & It3 & 9 & CN 842-1-891-1 & AJ608871-AJ608879 \\
\hline & Toscania & It 4 & 4 & CN 1268-1-1268-4 & AJ608880-AJ608883 \\
\hline Slovakia & Kosicky kraj & Sa1 & 6 & CN 1103-1-1121-1 & AJ608903-AJ608908 \\
\hline \multirow[t]{4}{*}{ Spain } & Avila & S1 & 5 & CN 1211-1-1212-3 & AJ608815-AJ608818 \\
\hline & Almeria & $\mathrm{S} 2$ & 6 & CN 1213-1-1214-2 & AJ608819-AJ608823 \\
\hline & Cataluna & S3 & 10 & CN 780-1-821-1 & AJ608805-AJ608814 \\
\hline & Navarra & $\mathrm{S} 4$ & 6 & CN 1215-1-1216-3 & AJ608824-AJ608828 \\
\hline
\end{tabular}


(5'-GRAATTTTGGTAGTATRTTRG-3') and 1R (5'- AGMACGYAAAATWGYAWAAGC-3') for the western European, northern European and Balkan clades, and 4F (5'-TTCAGATTGTYACYGGYAC-3') and 4R (5'-ACGGTAAAATTGTATAAGC-3') for the Italian clade. Amplification reactions were carried out in $2 \times 50 \mu \mathrm{L}$ volumes including $15 \mu \mathrm{L}$ of each $2 \mu \mathrm{M}$ primer, $17 \mu \mathrm{L}$ of $1 \mathrm{~mm} \mathrm{dNTP}, 10 \mu \mathrm{L}$ of $10 \times$ reaction buffer, $30 \mu \mathrm{L}$ of purified water, $2.8 \mu \mathrm{L}$ DMSO and $0.2 \mu \mathrm{L}$ of $5 \mathrm{U} / \mu \mathrm{L}$ Promega Taq DNA polymerase. PCR amplification used $10 \mu \mathrm{L}$ of DNA extract. Amplifications were performed in a Labover PTC100 Thermal Cycler employing 40 cycles $\left(45 \mathrm{~s}\right.$ at $94^{\circ} \mathrm{C}, 30 \mathrm{~s}$ at $48^{\circ} \mathrm{C}$ and $2 \mathrm{~min}$ at $68^{\circ} \mathrm{C}$ ) with a final extension cycle of $10 \mathrm{~min}$ at $68^{\circ} \mathrm{C}$. PCR products were purified using the Ultrafree DA Amicon Kit (Millipore) and directly sequenced. Both strands were sequenced using a BigDye Terminator (Applied Biosystems) sequencing kit on an ABI 310 (Applied Biosystems) automated sequencer.

\section{Data analysis}

Phylogenetic and network analyses. Cyt $b$ sequences were aligned using the MUsT package (Philippe 1993). The $H$. polygyrus data matrix was composed of 136 sequences; Heligmosomoides kurilensis kobayashii (Asakawa \& Ohbayashi 1986), and Heligmosomum costellatum (Dujardin, 1845) were used as outgroups. Sequences pertaining to the same haplotype were removed from the analyses. The mean transition to transversion ratio was estimated using the MUST package and the nucleotide frequencies were provided by the PAUP 4.0b8 package (Swofford 1998).

$H$. polygyrus data were analysed by distance (neighbourjoining or NJ) using PAUP 4.0b8 package, maximum likelihood (ML) using PHYML package (Guindon \& Gascuel 2003) and Bayesian-based inference as implemented in MRBAYES 3.0 (Huelsenbeck et al. 2001). The Akaike information criterion (AIC) in MODELTEST version 3.06 (Posada \& Crandall 1998) was used to determine the best-fit substitution model for the parasite data in the NJ and ML reconstructions, which was GTR + I + G. The Bayesian analysis was performed with the Metropolis-coupled Markov chain Monte Carlo algorithm. The tree-space was explored by using four chains run during 1 million generations. We used a generaltime-reversible model of sequence evolution allowing four among-site rate variation categories.

The robustness of inferences was assessed by bootstrap resampling (BP) (Felsenstein 1985) using 1000 random NJ repetitions and 10000 random ML repetitions. Bayesian posterior probabilities were obtained from the $50 \%$ majority rules consensus of trees sampled every 100 generations, after removing trees obtained before chains reached apparent stationarity ('burn in' determined by empirical checking of likelihood values at 300000 generations). Bayesian bootstrapping was performed as proposed by Douady et al. (2003): 110 pseudoreplicates of the data set were explored during 1 million generations by three chains and a general-time-reversible model of sequence evolution allowing a gamma shape of among-site rate variation. Burn-in value for each of the 110 replicates was fixed at 500000 generations. Overall Bayesian bootstrap support was obtained by computing the consensus of the consensus corresponding to each pseudoreplicates. Here, and unlike in previous studies, some of the pseudoreplicates did not converged prior to 500000 generations. They were not added to the 110 pseudoreplicates that did converged and it is likely that this decision had an impact on support values. However, and based the overall agreement between NJ, ML and Bayesian support values, we do not think that this could change our inferences.

Sequences differing only by one or two autapomorphies were considered as belonging to a unique haplotype in the network analyses. The data matrix comprised 108 haplotypes and $H$. kurilensis kobayashii and H. costellatum as outgroups. Networks were constructed using the minimum spanning network method (MINSPNET in ARLEQUIN 2.0, Schneider et al. 2000), statistical parsimony (тCS, Clement et al. 2000) and median-joining network (Bandelt et al. 1999; NETWORK 4.000 available at www.fluxus-engineering.com).

Phylogeographical and genetic structure analyses. The following analyses were realized on the complete data matrix - 136 sequences and $H$. kurilensis kobayashii and $H$. costellatum as outgroups.

A 'mismatch distribution' of substitutional differences between pairs of haplotypes was calculated within each of the main genetic lineages and compared with a fit to the Poisson model using DNAsP version 4.0 (Rozas \& Rozas 1997). This analysis provided an estimate of the population dynamics - either in recent expansion or rather stable in time - in the different lineages.

Population genetic structure and differentiation was determined by analysing the molecular variance (AMOVA available in ARLEQUIN 2.0 program). This method estimates the proportion of genetic variation at different hierarchical levels by using information from the geographical distribution of haplotypes and the pairwise distance between them. This analysis was performed at different hierarchical levels: among geographical groups of populations as defined in Fig. 1 (Spain, France, Belgium, Italy, Balkans, Ireland and Denmark); among populations within each geographical group (22 populations of $H$. polygyrus were defined according to geographical, ecological and geological data, see Fig. 1); and within populations.

Nucleotide $\left(p^{i}\right)$ and haplotype $(h)$ diversities were estimated using the DNASP version 4.0 program (Rozas \& Rozas 1997), while genetic distances between the groups of samples were obtained using a distance analysis (Kimura's 2 parameters distance estimator, $\left.\mathrm{K}_{2} \mathrm{P}\right)$. The estimation of 
nucleotide ( $p^{i}$ ) and haplotype ( $h$ ) diversities, and mean GD were calculated at different structural levels: first, each clade defined by the phylogenetic and networks analyses was analysed individually, and clade 3 was divided into two geographical groups, the first corresponding to the Iberian populations (group 3SW) and the second to all other northern populations (group 3No). These analyses were performed to assess whether nucleotide diversity was higher within the potential refuge regions as compared to northern populations. Second, nucleotide $\left(p^{i}\right)$ and haplotypes (h) diversities and mean GD were also estimated at two different structural levels, for (a) individuals belonging to a single host (intrahost values) in comparison to individuals belonging to different hosts of the same population (interhosts values), in the Italian (It1) and Belgian (B1) host populations; (b) for populations belonging to a same clade (intraclades values) in comparison with populations belonging to different clades (interclades values).

Estimation of time differentiation. As populations of recent origin may not be at genetic equilibrium, the estimate of the timing of intraspecific divergence must be interpreted cautiously. Therefore, an approximate timing of divergence between the observed mtDNA lineages was calculated on the basis of the percentage of genetic divergence (GD) obtained with a distance analysis ( $\mathrm{K}_{2} \mathrm{P}$ distance), and was corrected for ancestral mtDNA polymorphism, as proposed by Avise (2000) using the formula:

$P_{\text {net }}=P_{\mathrm{AB}}-0.5\left(P_{\mathrm{A}}+P_{\mathrm{B}}\right)$

where $P_{\text {net }}$ is the corrected distance between the isolated lineages $\mathrm{A}$ and $\mathrm{B}, P_{\mathrm{AB}}$ is the mean genetic distance in pairwise comparisons of individuals $\mathrm{A}$ vs. $\mathrm{B}$, and $P_{\mathrm{A}}$ and $P_{\mathrm{B}}$ are mean genetic distance among individuals within these lineages.

However, it is generally problematic to calibrate the absolute rate of evolution of invertebrate parasites because they lack fossil records. On the basis of the sequencing of orthologous DNA regions in both species (cyt $b$ gene), the comparison of the partial phylogeographical histories of H. polygyrus and its specific and direct host, A. sylvaticus, shows partial codifferentiation (Nieberding et al. 2004). This result allows the use of calibration points derived from palaeontological data of the genus Apodemus to date the internal nodes of the parasite (Page et al. 1998): the divergence time (mean $\mathrm{K}_{2} \mathrm{P}$ distances corrected for ancestral mtDNA polymorphism) calculated for the separation of A. sylvaticus lineages was assimilated to the corresponding lineages of $H$. polygyrus. This gives an estimated global molecular clock of 3.5\%-3.7\% sequence divergence per Myr for H. polygyrus (Nieberding et al. 2004). Therefore we can estimate the split between $H$. polygyrus clades using Avise formula and this rate.

\section{Results}

\section{Mitochondrial haplotype and nucleotide diversities}

A total of 126 haplotypes were identified among the 136 Heligmosomoides polygyrus cyt $b$ sequences (EMBL Accession nos AJ608805 to AJ608917 and AJ630628 to AJ630644). The matrix provided $687 \mathrm{bp}$ of which 212 sites were variable and 151 were parsimony informative. The mean transition to transversion ratio is 2.18 and the nucleotide frequencies are $25.68 \%, 5.73 \%, 19.62 \%, 48.97 \%$ for $\mathrm{A}, \mathrm{C}, \mathrm{G}$ and $\mathrm{T}$, respectively. The number of substitutions between haplotypes ranges from one to 101 . Sequences differing only by one or two autapomorphies were considered as belonging to a unique haplotype in the network analyses - the H. polygyrus data matrix in these analyses comprised 108 haplotypes.

\section{Phylogenetic and networks relationships of haplotypes}

The NJ, ML and Bayesian reconstruction analyses were performed on the complete $H$. polygyrus data matrix with the outgroups Heligmosomoides kurilensis kobayashii and Heligmosomum costellatum (Fig. 2). Five relatively well-supported (bootstrap resampling and posterior probabilities) genetic groups appear: the first one comprises the Italian populations (clade 1); the second one comprises the Iberian populations (clade 2), the third one covers southwestern and western Europe (Spain, France, Belgium; clade 3), Balkan populations form the clade 4, and the fifth one forms an Irish-Danish clade (clade 5). The five clades are separated by a high degree of GD (Fig. 2, Table 4). A signal was found to link the western European (clades 2 and 3) and Balkan clades (clade 4); however, the relationships between clades 1, 5 and the complex $(2,3,4)$ as well as the relationships inside the complex $(2,3,4)$ remain unclear.

The first clade is further divided into two allopatric subclades: a first one corresponding to the northern part of Italy (subclade 1a) and a second one comprising the populations from southern Italy and Sicily (subclade $1 b$ ); the Sicilian populations form a distinct subclade within subclade $1 b$ (subclade $1 b^{\prime}$ ). Moreover, the Irish (subclade $5 a$ ) and Danish (subclade 5b) populations are monophyletic inside the fifth clade.

Networks of the 108 haplotypes of $H$. polygyrus show a general congruence with the phylogenetic reconstructions. The minimum spanning network shows the five main groups defined above and separate them from each other by a genetic distance of 18-35 mutational steps (Fig. 3). The Italian clade is formed by three allopatric and distinct groups (subclades $1 \mathrm{a}, 1 \mathrm{~b}$ and $1 \mathrm{~b}^{\prime}$ ), linked by, respectively, 18 and 15 mutational steps. Moreover, the Irish and Danish populations form two distinct subclades inside clade 5 . The relationships among the major clades remain unresolved, at the exception of the western European and Balkan 


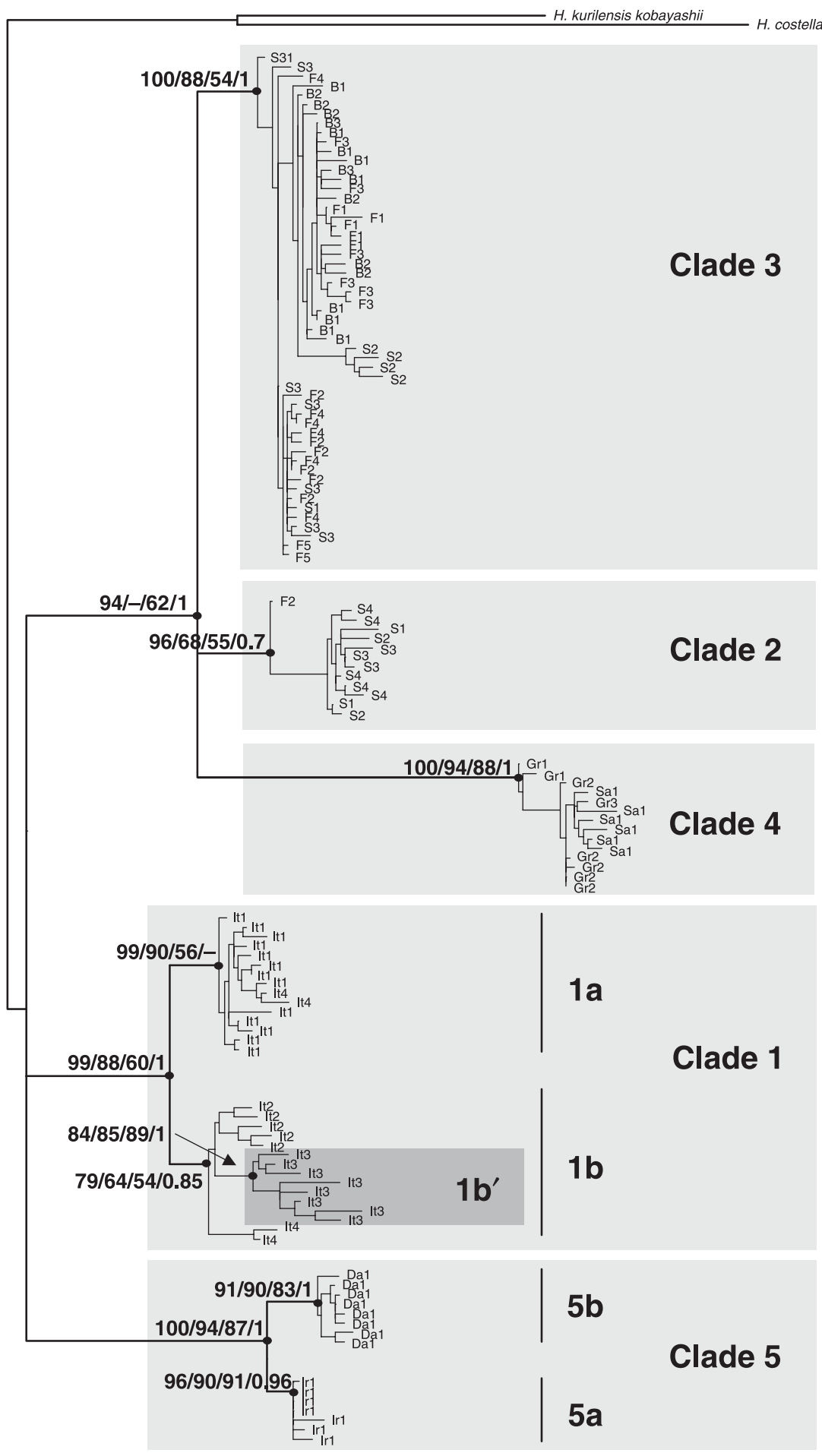

Fig. 2 Most likely tree of the PHYML reconstruction for the $126 \mathrm{mtDNA}$ haplotypes and the outgroups Heligmosomoides kurilensis kobayashii and Heligmosomum costellatum, represented by their geographical origins (see Table 1 and Fig. 1). Numbers on branches indicate, from left to right (a) bootstrap support obtained in the NJ reconstruction (GTR $+\mathrm{I}+\mathrm{G}$ ); (b) bootstrap support in the PHYML analysis (c) bootstrap support obtained in the Bayesian analysis; (d) Posterior probabilities in MRBAYES analysis. Note that Bootstrap values under $50 \%$ and posterior probabilities under 0.7 were not considered.

0.1

clades which are linked together with some bootstrap support. The genetic differentiation of the parasite is important: the mean number of mutational steps separating parasite haplotypes is high (6.3). Clade 3 is characterized by a star-like topology, suggesting that these populations are the result of a recent expansion from a small number of animals (Avise 2000). The other clades of H. polygyrus appear more heterogeneous.

However, the main difference in the minimum spanning network in comparison with the most likely topology is 


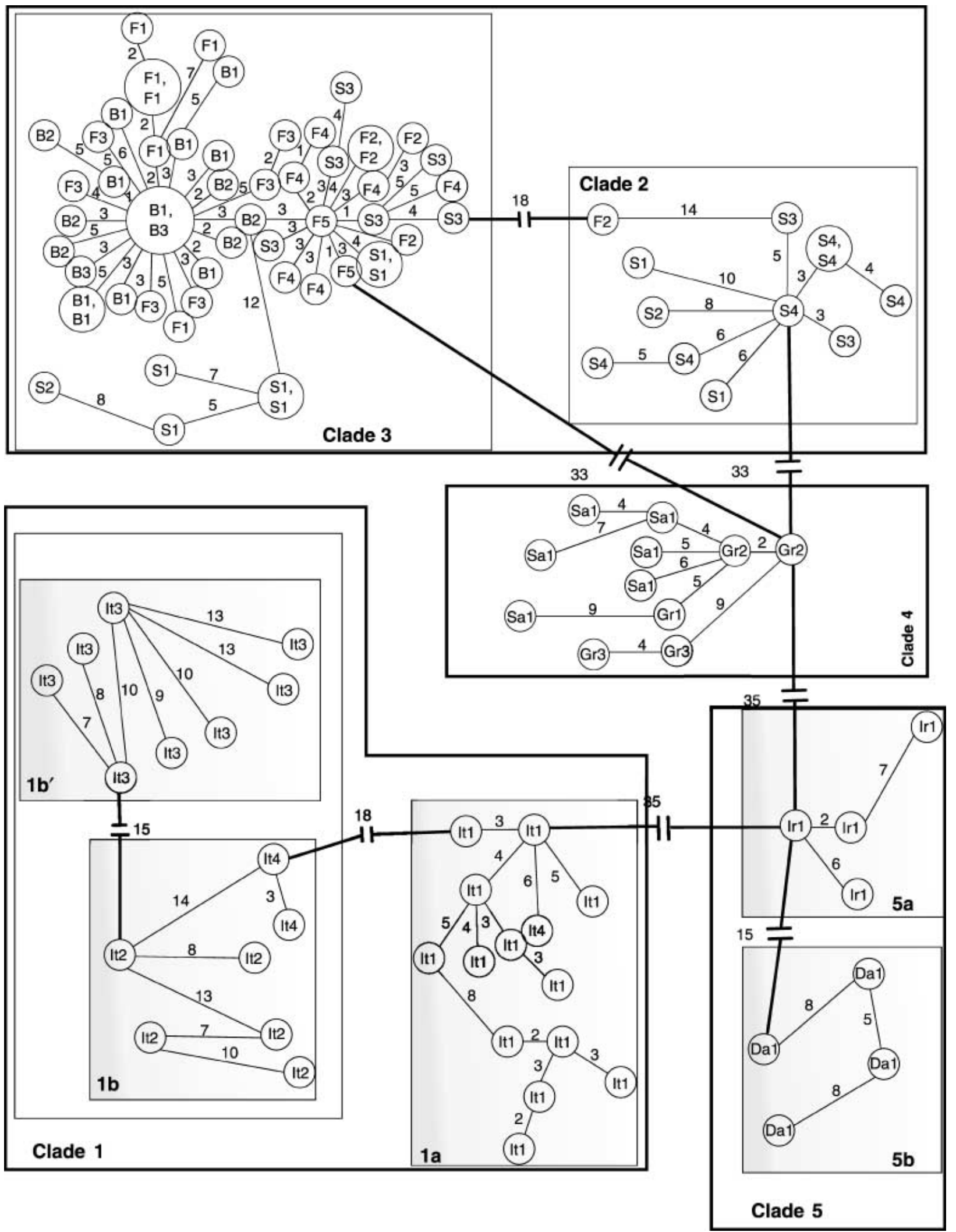

Fig. 3 A minimum spanning network constructed using the 108 haplotypes of mitochondrial $c y t b$ gene sequences. Geographic origins (Table 1 and Fig. 1) are noted. Numbers correspond to the mutational steps observed between haplotypes, and the size of the circle is proportional to the numbers of haplotypes represented. 


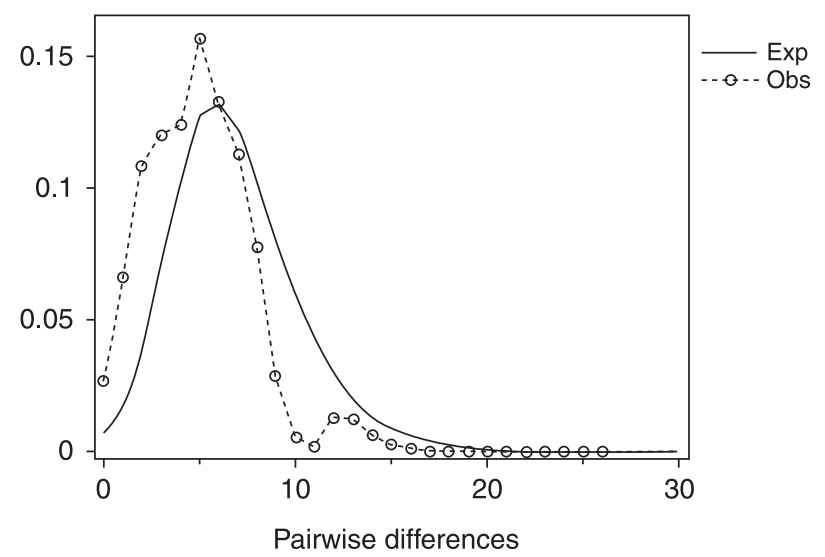

Fig. 4 Mismatch distribution for mtDNA types from $H$. polygyrus clade 3 . The expected frequencies, based on a population growthdecline model, using the DNASP version 4.0 program (Rozas \& Rozas 1997), is compared to experimental frequencies obtained in clade 3.

Table 2 AMova results, based on 687 bp of cyt $b$ gene of Heligmosomoides polygyrus

\begin{tabular}{ll} 
Source of variation & Per \\
\hline Among geographical groups & 69 \\
Among populations within groups & 14 \\
Within populations & 17
\end{tabular}

that clades 2 and 3 seem to be more closely related to each other than to any other haplotype (18 mutational steps). Median-joining and the TCs networks mostly corroborate minimum spanning network results (data not shown). Both methods present a high differentiation between the main clades, support the same substructure and connect the haplotypes of clade 3 in a star-like topology. Furthermore, TCs presents an extremely fragmented picture since the $95 \%$ connection limit did not allow to link groups that were more than 13 steps apart.

\section{Phylogeographical and population genetic structures}

AMOvA shows that majority of the total mtDNA variation $(69 \%)$ is distributed among the seven geographical groups of populations whereas a low percentage of this variation $(14 \%)$ is observed among populations within the main lineages (Table 2).

A signature of population growth - a bell-shaped distribution - (Fig. 4) is evident in the distribution of substitutional differences in clade 3 , as would be expected for populations expanding after the last ice age from a relatively few founder individuals (Luikart et al. 2001). On the contrary, the distribution appears more heterogeneous for the other lineages, suggesting more stable populations less subject to a recent expansion (data not shown).

The estimation of nucleotide $\left(p^{i}\right)$ and haplotypes $(h)$ diversities, and mean GD were calculated at different structural levels. First, to assess whether nucleotide diversity was higher within the potential refuge regions as compared to northern populations, clade 3 was divided into two geographical subgroups: the first corresponding to the Iberian populations (group 3SW) and the second to all other northern populations (group 3No) (Table 5). Within the six groups, the group $3 S W$ is characterized by a significantly higher $p^{i}(P<0.001$, Student's $t$-test $)$ and mean GD $(P<0.001$, Kruskal-Wallis test $)$ than the group 3No. Subclade $3 \mathrm{No}$, clades 2, 4 and 5 show low levels of GD, $p^{i}$ and $h$, which may reflect genetic bottlenecks or recent population expansion from a small number of founder individuals. Subclades $1 \mathrm{a}$ and $1 \mathrm{~b}$ present high levels of mean GD, $p^{i}$ and $\mathrm{h}$, typical of stable populations with large long-term $N_{e}$. Second, nucleotide $\left(p^{i}\right)$ and haplotypes $(h)$ diversities, and mean GD were also calculated at other structural levels, as explained in the Materials and methods. We compared the diversity of individuals belonging to: (i) a single or to different hosts of the same population, or (ii) to the same or to different clades. First, the analysis was performed on the Italian (It1) and the Belgian (B1) populations (Table 3). Although statistically different $(P<0.05$, Student's $t$-test), mean GD and $p^{i}$ diversity values are even higher within a single host than between different hosts in the Belgian population. Therefore, parasites found in the same host were no more related to each other than others living in different hosts. Thus, they can all be considered as distinct samples. And second (Table 4), mean GD was more than three times higher and mean $p^{i}$ about twice higher for populations

Table 3 Genetic variability observed among Heligmosomoides polygyrus individuals present in a single host (intrahost) or in different hosts (interhost) of a population

\begin{tabular}{|c|c|c|c|c|c|c|}
\hline Populations & & $\begin{array}{l}\text { Sample } \\
\text { size }\end{array}$ & $\begin{array}{l}\text { Number of } \\
\text { haplotypes }\end{array}$ & $\begin{array}{l}\mathrm{GD} \\
(\%) \pm \mathrm{SD}\end{array}$ & $\begin{array}{l}\text { Nucleotide } \\
\text { diversity }\left(p^{i}\right) \pm \mathrm{SD}\end{array}$ & $\begin{array}{l}\text { Haplotype diversity } \\
\text { (h) } \pm \text { SD }\end{array}$ \\
\hline \multirow[t]{2}{*}{ B1 } & intrahost & 15 & 9 & $1.85 \pm 0.01$ & $0.018 \pm 0.002$ & $0.924 \pm 0.044$ \\
\hline & interhost & 10 & 9 & $1.08 \pm 0.01$ & $0.011 \pm 0.001$ & $0.978 \pm 0.054$ \\
\hline \multirow[t]{2}{*}{ It1 } & intrahost & 8 & 8 & $1.21 \pm 0.01$ & $0.010 \pm 0.001$ & $1 \pm 0.063$ \\
\hline & interhost & 8 & 8 & $1.64 \pm 0.01$ & $0.014 \pm 0.003$ & $1 \pm 0.063$ \\
\hline
\end{tabular}

SD, standard deviation; B1, Belgian population and It1, Italian populations (Table 1 and Fig. 1). 
Table 4 Mean genetic diversity observed among Heligmosomoides polygyrus individuals sampled within a clade (intraclade) and sampled in different clades (interclade)

\begin{tabular}{llll}
\hline & Mean GD (\%) & Mean $p^{i}$ & Mean $h$ \\
\hline Intra-clades & 2.36 & 0.020 & 0.977 \\
Inter-clades & 9.03 & 0.039 & 0.975 \\
\hline
\end{tabular}

belonging to different clades in comparison with intraclades values; mean $h$ values remained unchanged.

\section{Estimation of divergence time among clades}

The partial synchronous codifferentiation of the phylogeographical patterns of $H$. polygyrus and its specific and direct host, A. sylvaticus, is discussed elsewhere (Nieberding et al. 2004). The rate of 3.5\%-3.7\% sequence divergence per Myr in $H$. polygyrus was applied in this study to estimate the differentiation time between the five main lineages of $H$. polygyrus (Table 4): their absolute time of differentiation took place between $2.47 \pm 0.24$ and $1.55 \pm$ $0.23 \mathrm{Myr}$. The order of formation and the time of isolation of the five clades can not be defined more precisely, given their nearly equal genetic distance from each other and the lack of phylogenetic signal. Moreover, the isolation of the Sicilian populations from the Italian continental ones occurred about $0.53 \pm 0.23$ to $0.56 \pm 0.24 \mathrm{Myr}$, while differentiation between clades $1 \mathrm{a}$ and $1 \mathrm{~b}$ took place about $1.3 \pm 0.22$ Myr.

\section{Discussion}

\section{Genetic structure and diversity: particularities of Heligmosomoides polygyrus phylogeographical pattern}

Heligmosomoides polygyrus' mean cyt $b$ genetic diversity and differentiation (6.7\% of GD in the whole data set) is high in comparison with general results obtained on vertebrate taxa: indeed, Avise et al. (1998) reported values ranging from $2.2 \%, 2.4 \%, 2.6 \%$ to $3.1 \%$ within bird, mammal, fish and reptile species, respectively. Compared to data on invertebrate taxa, $H$. polygyrus' genetic diversity appears more relative: butterflies present generally low level of genetic differentiation, according to their high flight dispersal abilities (Vandewoestijne et al. 2004), while snails like Biomphalaria glabrata, insects like Maoricicada campbelli, Peltoperla tarteri, or Tarphius canariensis and other invertebrates exhibit values similar to those of $H$. polygyrus (Emerson et al. 2000; Buckley et al. 2001; Trewick \& Wallis 2001; Mavarez et al. 2002; Schultheis et al. 2002). Paranoplocephala arctica, a cestode parasitizing collared lemmings in the northern Holarctic region, presents a global GD of $4.5 \%$, a value intermediate to the one observed in this study (Wickström et al. 2003).
H. polygyrus' pattern of high genetic diversity is confirmed by high within-clade diversity and interclades differentiation (Table 4) of the same order as in other trichostrongyloïd nematodes (Anderson et al. 1998) and cestodes of mobile vertebrates (Wickström et al. 2003).

According to Frankham et al. (2002), the genetic diversity and differentiation in populations depend on migration (gene flow), breeding system, current and historical $N_{e}$ (demographic events), and mutation rate $\mu$.

First, $H$. polygyrus' gene flow is primarily determined by its host contacts and movements, according to host-parasite specificity, direct life cycle of the parasite, short survival time of larvae at free stage and limited dispersal abilities by its own (Blouin et al. 1995). For example, parasitic lice on doves exhibit a strong geographical differentiation correlated to their host-limited dispersion (Johnson et al. 2002), while the populations of the tick Ixodes uriae on the Atlantic puffin Fratercula arctica display an opposite pattern (McCoy et al. 2003).

Second, the parasite presents only sexual reproduction, larvae are emitted in the host faeces which have to be ingested by a host, and adults have to meet in A. sylvaticus intestine to reproduce. As only half of the wood mice are infected (prevalence of 50\%, Goüy de Bellocq et al. 2003), and as transmission by infected migrants might not be successful because nematodes might not be adapted to a new environment, gene flow between parasite populations lags behind that of their hosts. This kind of barriers should promote parasite differentiation. Indeed, this study showed that:

1 H. polygyrus' GD within host population - either intrahost or interhost diversity - is about $1.5 \%$ (Table 3 ). This is likely the consequence of $H$. polygyrus reproductive mode: infrapopulations in hosts are formed by recruitment (immigration) from the metapopulation and not as a result of natality within the host (Nadler 1995). Therefore, successful reproduction between wood mice does not guarantee successful $H$. polygyrus populations genetic mixing in their intestines.

2 H. polygyrus' mean GD and mean $p^{i}$ were about three and two times higher between populations belonging to different clades in comparison with intraclades values, while mean $h$ values remained unchanged (Table 4 ). These results highlight that population differentiation sets up by the accumulation of mutations between allopatric populations and disappearance of intermediate haplotypes because of lack of gene flow. As such, parasite's limited gene flow between host populations promotes parasite allopatric genetic differentiation (Viney 1998).

Thirdly, phylogeographical data sets are not appropriate to estimate $N_{e}$ because they can not be considered as a single population from an extended temporal perspective 
(large, high gene flow and historically nonsundered population) (Avise 2000). In a phylogeographical context, $N_{e}$ does not depend on the current intrinsic diversity but rather on the species demographic history in the evolutionary time (Avise 2000). However, the mtDNA diversity in parasitic nematodes depends on the abundance and prevalence of the parasite in its host, two factors that directly affect $N_{e}$ (Blouin 1998). We may therefore propose the following scheme: the abundance and prevalence of $H$. polygyrus on $A$. sylvaticus are quite high, involving a rapid accumulation of mutations and ensuring the parasite genetic diversity. Blouin (1998) and Anderson et al. (1998) showed that trichostrongyloïd nematodes species present high level of mtDNA diversity because they have an obligate outcrossing breeding system and enormous standing populations (abundance and prevalence), two factors directly affecting $N_{e}$.

Fourthly, high sequence diversity could also result from an accelerated rate of nucleotide substitution (Blouin et al. 1995). Indeed, we evidenced previously that the rate of molecular evolution of $c y t b$ is high in $H$. polygyrus: about $3.5 \%-3.7 \% \mathrm{~K}_{2} \mathrm{P}$ distance per Myr between $H$. polygyrus lineages, about twice higher than the widely used $2 \%$ for invertebrate mitochondrial sequences (e.g. Gomez et al. 2000; Nieberding et al. 2004). This result agrees with those of other phylogenetic studies that pointed out faster molecular evolutionary rate of mtDNA of nematodes, compared to all other animal taxa (Blouin et al. 1998; Denver et al. 2000).

Therefore, nematode parasites may serve as biological markers or 'magnifying glasses' of their hosts, pointing at finer temporal and geographical scales events that are not (or not as clearly) apparent in their hosts phylogeographical history (Thomas et al. 1996; Wickström et al. 2003; Nieberding et al. 2004). Several cases of cryptic host divergence highlighted by $H$. polygyrus phylogeographical pattern are described further in the discussion.

\section{Phylogeographical pattern of $\mathrm{H}$. polygyrus}

Importance of allopatric differentiation in H. polygyrus. The three different networks and the phylogenetic analyses all detected that $H$. polygyrus is formed by five main units that have mainly a nonoverlapping geographical distribution: Italy (clade 1), Ireland-Denmark (clade 5), Spain (clade 2), western Europe (clade 3) and the Balkans (clade 4). The first two units are further divided in different subclades: northern vs. southern Italy, with a secondary differentiation of Sicilian haplotypes; Ireland vs. Denmark, respectively. The association of western European and the Balkan clades may reflect that lineages originating from Iberia and western Europe moved across Europe to the Balkans and vice versa during interglacial periods of early Quaternary. However, lineages mixing should have stopped and differentiation should have begun early during Pleistocene since the Balkan clade presents a long branch showing long-term isolation (Fig. 2). Further, the relationships among all five clades remained unclear whatever the method used. This may reflect a lack of information available in the sequences: all clades seem to have differentiated in allopatry as the result of an ancient geographical isolation during the Quaternary. Indeed, the geographical differentiation of $H$. polygyrus is highly supported as $69 \%$ of the total mtDNA variation (Fig. 1 and Table 2) is distributed among the main geographical groups of populations. All differentiation events between the five main units took place between $2.47 \pm 0.24$ and $1.55 \pm 0.23 \mathrm{Myr}$; the time of isolation of the five lineages can not be defined more precisely. Similar difficulties to assess the internal relationships among clades of parasites also appeared on Paranoplocephala arctica (Anoplocephalidae, Cestoda) (Wickström et al. 2003), and highlights the importance of geographical allopatric differentiation and speciation in parasite helminths.

Refuge regions and postglacial recolonization. The analysis of nucleotide diversity and of mismatch distribution (Table 5 and Fig. 4) confirms that the Iberian Peninsula was a refuge region for $H$. polygyrus, and that the parasite recolonized and expanded in the main part of the western Palearctic region from southwestern Europe at the end of the last ice age. The Pyrenees were not an effective barrier to the parasite's northward expansion. This result is similar to that obtained on its specific host A. sylvaticus (Michaux et al. 1998, 2003), and confirms a strong relationship between the phylogeographical histories of these two species (Nieberding et al. 2004). However, unlike A. sylvaticus, H. polygyrus presents a second distinct and partially syntopic (i.e. in close physical proximity because both clades share the same host populations and therefore the same habitat) clade 2 in the Iberian Peninsula. This strongly suggests that there were at least two allopatric glacial refuge areas for the parasite in Spain during the Quaternary ice ages, of which only one (clade 3 ) contributed to the northern recolonization of western Europe. Other studies showed the existence of several distinct refuges in this Mediterranean region during the past 2 Myr (Gomez et al. 2000; Queney et al. 2001).

Italy and the Balkans seem to have constituted two distinct refuges for the parasite and its host. As in A. sylvaticus, $H$. polygyrus Balkan clade is characterized by a lower genetic diversity than group 3SW and clade 1 (Table 5), which could be explained by a genetic bottleneck that appeared during one of the last ice ages in both species (Michaux et al. 2003; for more details, see Nieberding et al. 2004). The two clades should have been restricted in their northern expansion at the end of the last ice age by the presence of topographic obstacles as the Alps and the Carpathian Mountains. 
Table 5 Genetic variability observed within the five main genetic lineages of Heligmosomoides polygyrus. Clade 3 was divided into two different subgroups corresponding to the southern populations (subgroup 3SW; populations S1-S4) and more northern populations (subgroup 3No; populations B1-3, F1-F5)

\begin{tabular}{|c|c|c|c|c|c|}
\hline Groups & $\begin{array}{l}\text { Sample } \\
\text { size }\end{array}$ & $\begin{array}{l}\text { Haplotypes } \\
\text { number }\end{array}$ & $\begin{array}{l}\text { Mean genetic } \\
\text { divergence } \\
(\mathrm{GD}, \%) \pm S D\end{array}$ & $\begin{array}{l}\text { Nucleotide } \\
\text { diversity }(ð) \pm S D\end{array}$ & $\begin{array}{l}\text { Haplotype } \\
\text { diversity }(h) \pm \mathrm{SD}\end{array}$ \\
\hline Clade 1a & 15 & 14 & $2.67 \pm 0.01$ & $0.026 \pm 0.003$ & $0.992 \pm 0.015$ \\
\hline Clade 1b & 8 & 7 & $2.38 \pm 0.01$ & $0.025 \pm 0.003$ & $0.993 \pm 0.017$ \\
\hline Clade $1 b^{\prime}$ & 9 & 8 & $2.78 \pm 0.01$ & $0.022 \pm 0.002$ & $0.994 \pm 0.045$ \\
\hline Clade 2 & 14 & 12 & $1.99 \pm 0.02$ & $0.018 \pm 0.006$ & $0.995 \pm 0.034$ \\
\hline Group 3No & 46 & 26 & $1.46 \pm 0.06$ & $0.012 \pm 0.001$ & $0.997 \pm 0.012$ \\
\hline Group 3SW & 14 & 13 & $2.50 \pm 0.02$ & $0.023 \pm 0.005$ & $0.997 \pm 0.023$ \\
\hline Clade 4 & 15 & 11 & $1.35 \pm 0.01$ & $0.012 \pm 0.002$ & $0.981 \pm 0.031$ \\
\hline Clade 5 & 15 & 8 & $1.79 \pm 0.01$ & $0.017 \pm 0.001$ & $0.943 \pm 0.054$ \\
\hline
\end{tabular}

$\mathrm{SD}$, standard deviation.

In Italy, two other isolation events likely took place in $H$. polygyrus, between (i) northern and southern continental populations, and (ii) Sicilian populations from the peninsular ones. In A. sylvaticus, the Sicilian populations are also well differentiated from the peninsular ones (Michaux et al. 2003). The differentiation of Sicilian populations of both species is ancient and is estimated to have occurred $0.55 \pm 0.24 \mathrm{Myr}$ in H. polygyrus, and $0.90 \pm 0.15 \mathrm{Myr}$ in $A$. sylvaticus (Michaux et al. 2003). Sicilian populations of both species were stable over time, as shown by genetic diversity and mismatch distribution analyses (Fig. 3 and Michaux et al. 2003).

Up to now, two alternative hypotheses could explain the ancient isolation of Sicilian wood mouse populations (Michaux et al. 2003): (i) the Sicilian populations were isolated from the continent for $0.8 \mathrm{Myr}$, allowing ancestral haplotypes to survive and diverge. However, palaeontological and geological data attest the presence of $A$. sylvaticus in Sicily for only 70000-50 000 years BP (Sara, personal communication) and several connections between Sicily and Italy existed for the last Myr (Thaler 1973; Jaeger, personal communication); and (ii) an old lineage survived in southern Italy and entered Sicily during the last glaciation, 70000 years BP. This ancient stock remained trapped in the island until present and suffered less from the last ice age, whereas the southern continental population was replaced by a 'modern stock' spreading from other Italo-Balkan refuges during the postglacial era.

The results obtained on $H$. polygyrus are best explained by the second hypothesis. Indeed, the Sicilian parasite population is closely related to the southern Italian one (Figs 2 and 3), which could be interpreted as a biological print evidencing strong association between the Sicilian and Calabrian A. sylvaticus during the Quaternary. Indeed, southern Italy was isolated several times by the sea from the northern part of the country (Jaeger, personal communication).
A. sylvaticus Calabrian population disappeared recently, after transmission of its parasite populations to a 'modern stock' of wood mice spreading from other Italo-Balkan refuges.

Regardless, the results obtained on $H$. polygyrus suggest the existence of two allopatric glacial refuge areas in continental Italy during the Quaternary. Moreover, the high genetic diversity of Sicilian $H$. polygyrus populations confirms the role of this area as 'hot spot' of intraspecific biodiversity for this species as it has already been pointed out for different species (Michaux et al. 2003).

Northern refuge in the southern British Isles. H. polygyrus presents a distinct and robust northern clade in Ireland and Denmark. Its differentiation time is estimated between $2.02 \pm 0.21$ and $1.46 \pm 0.19$ Myr. This result contrasts with the traditional biogeographical model of temperate species in Europe which predicts that temperate-adapted species survived the glacial periods of the Pleistocene in refuges located in the southern European peninsulas of Iberia, Italy and the Balkan or in Eastern regions (Bilton et al. 1998), and recolonized the British Isles and northern Europe from these southern refuges [e.g. oaks, shrews, hedgehogs and bears from Spain, and grasshoppers, alder, beech and newts from the Balkans (Hewitt 2000)].

H. polygyrus' northern clade may have differentiated and survived to the Quaternary ice ages in the southern part of the British Isles or elsewhere further south in continental Europe. Indeed, because of limited sampling, we can not exclude that the parasite's northern clade is part of a more broadly distributed lineage that differentiated somewhere in continental Europe.

However, an increasing number of studies propose the presence of a disjunctive refuge in the southern part of the British Isles or on a land area formed by the exposed bed of the southern North Sea that existed during glacial maxima 
(Stewart \& Lister 2001; Hänfling et al. 2002; Tzedakis 2003). Indeed, the southern part of Great Britain was never covered by ice and land bridges periodically existed between Great Britain and the European continent in the Dover isthmus region during the cold stages (Jones \& Keen 1993).

Moreover, during the first part of the early Pleistocene period, from 2.4 to $1.6 \mathrm{Myr}$, and during the later temperate stages, the southern part of Great Britain was covered by mixed, temperate forest, and species of Pinus, Alnus, Picea, Betula, Ulmus, and Cervus were present (Jones \& Keen 1993). Further, different species like Pinus sylvestris (Sinclair et al. 1999), Carex digitata (Tyler 2002), Arbutus unedo (Stewart 2003), as well as several species of fishes and land snails (Koskinen et al. 2000; Hänfling et al. 2002; Pfenninger et al. 2003), present a distinct and ancient northern lineage in the southern British Isles. In this context, a northern lineage of $H$. polygyrus on $A$. sylvaticus may have survived glaciations in local periglacial refuges with suitable microclimates. Indeed, behavioural accommodation and facultative adaptation of $A$. sylvaticus may be invoked to explain its presence in a possibly treeless region during previous ice ages: it presents in fact a large, ubiquitous ecological niche, from open field to woodland biota (Flowerdew 1991).

However, the northern populations of A. sylvaticus in Britain, Ireland and Denmark do not present any differentiation pattern from the southwestern European ones (Michaux et al. 2003 and unpublished). Therefore, two possibly complementary - hypotheses may explain this incongruence. First, as shown previously, the relative rate of molecular evolution of the H. polygyrus cyt $b$ is about 1.5fold higher than that of its host. This underlines that the $A$. sylvaticus cyt $b$ gene has a more limited power to disclose differentiation phenomena, like a possible isolation of the northern populations. This would be one more case of H. polygyrus 'magnifying glass effect' on past biogeographical events of its host. However, it should be quite surprising that such an ancient event observed in the parasite (estimated to 2.02-1.46 Myr) would not be reflected in the phylogeographical structure of $A$. sylvaticus. Second, northern rodent populations that survived and differentiated during the Pleistocene may have been replaced by the Iberian pool at the end of the last ice age. This event should have been accompanied by a host switch of northern $H$. polygyrus populations on the invading host lineage. In favour of this hypothesis, it may be assumed that:

1 The northern populations of either species were small and had likely experienced a bottleneck, according to the low genetic diversity of $H$. polygyrus northern group. The small size of local host populations may have facilitated their disappearance at the arrival of western European lineage vigorous invaders.

2 A. sylvaticus' invaders may have lost part of their parasite fauna during the recolonization process, facilitating the assimilation of new parasites populations. Indeed, current invasive species in Europe have been shown to present $50 \%-77 \%$ less parasites species than continental ones (Donnars 2003).

Therefore, at the end of the last glaciation, the western European populations of $A$. sylvaticus, expanding from the Iberian Peninsula, may have reached northern Europe and replaced the ancestral local populations, accompanied by a host switch of northern $H$. polygyrus populations on the invading host lineage. Then western European populations of $A$. sylvaticus likely recolonized the northern parts of Europe towards Ireland in the west and Denmark in the east. The land bridge between Great Britain and the continent was maintained up to $8250 \mathrm{BP}$, allowing the migration from southern England to Denmark (Jones \& Keen 1993). In contrast, it seems that there has been no connection between England and Ireland during the Holocene (Yalden 1982); therefore, the recolonization of Ireland by $A$. sylvaticus and $H$. polygyrus may have been achieved very recently thanks to human transport or raft. In favour of this hypothesis, the genetic diversity of $H$. polygyrus' Irish population is extremely low and may be the consequence of a genetic bottleneck following the colonization of the island by a small number of founder individuals $\left(0.7 \% \mathrm{~K}_{2} \mathrm{P}\right.$ distance; $\left.h=0.714 \pm 0.181 ; p^{i}=0.006 \pm 0.002\right)$.

\section{Conclusions}

This study established the phylogeographical pattern of the European nematode Heligmosomoides polygyrus. The existence in $H$. polygyrus of highly differentiated lineages that survived in the southern European peninsulas during the Quaternary ice ages - like in Italy (clade 1), in the Balkans (clade 4) and in Spain (clades 2 and 3), and of postglacial recolonization of western Europe from Spain (clade 3) - shows that Pleistocene climatic changes may have affected helminth parasites and free-living organisms in a similar way. Particularly, the existence of a northern and highly differentiated lineage in Ireland and Denmark (clade 5) suggests the existence of forested, temperate and permanent refuges in northern Europe during the Quaternary. The uncertainty about the relationships and the differentiation time among the five main lineages highlight the importance of allopatric differentiation and speciation in parasite helminths.

A previous study had highlighted synchronous codifferentiation of $H$. polygyrus and its host in western Europe, Italy and Sicily (Nieberding et al. 2004). In these regions, the parasite acts as a biological magnifying glass as it revealed previously undetected phylogeographical information in the host, such as distinct allopatric refuges in the Italian and Iberian peninsulas, and historically persistent gene flow between Sicily and southern Italy. The extension 
of the study of $H$. polygyrus phylogeographical pattern to northern (Ireland and Denmark) and eastern (the Balkans) Europe shows that, in these regions, the parasite displays a particular phylogeographical history when compared to its specific host, as it differentiated while its host populations remained undifferentiated.

Eventually, this confirms most studies working on the interspecific level, that show that the phylogenetic history of current 'specific' parasite species are generally very different from the one of their obligate host: long-term codifferentiation over a large spatial scale is the exception. Therefore, the present data propose how and why an intraspecific codifferentiation process may occur on the midrange of the evolutionary timescale: sporadic gene flow between distant host populations are not transmitted in their parasites' populations. As such, parasite's limited gene flow between host populations promotes parasite allopatric genetic differentiation and, from a macroevolutionary perspective, reduces congruence (Blouin et al. 1995; Clayton et al. 2003).

\section{Acknowledgements}

We thank F. Audebert, S. Baird, W. Booth, S. Caro, JC. Casanova, V. Deffontaine, M. C. Durette-Desset, C. Feliu, R. Fons, J. Goüy de Bellocq, T. Hansen, F. Hourlay, T. Jensen, P. Lymberakis, E. Magnanou, J. Miquel, I. Montgomery, JL Nieberding, A. Ribas and H. Suzuki for providing pieces of advice, $H$. polygyrus and outgroups samples or for morphological determination. We thank also R. Petit and one anonymous reviewer for their helpful comments on the manuscript.

This work was supported by a Belgian Fond National de la Recherche Scientifique fellowship to C. Nieberding (mandat 'aspirant') and to J.R. Michaux (mandat 'chercheur qualifié'), a financial grant of the Belgian FNRS (crédits pour brefs séjours à l'étranger to $\mathrm{CN}$ and RL) and of the Institut Français de la Biodiversité (IFB).

\section{References}

Anderson TJ, Blouin MS, Beech RN (1998) Population biology of parasitic nematodes: applications of genetic markers. Advances in Parasitology, 41, 219-283.

Attwood SW (2001) Schistosomiasis in the Mekong region: epidemiology and phylogeography. Advances in Parasitology, 50, 88-152.

Avise JC (2000) Phylogeography. The History and Formation of Species. Harvard University Press, Cambridge, MA.

Avise JC, Walker D, Johns GC (1998) Speciation durations and Pleistocene effects on vertebrate phylogeography. Proceedings of the Royal Society of London. Series B, Biological Sciences, 265, 1707-1712.

Bandelt HJ, Forster P, Rohl A (1999) Median-joining networks for inferring intraspecific phylogenies. Molecular Biology and Evolution, 16, 37-48.

Bilton DT, Mirol PM, Mascheretti S, Fredga F, Zima J, Searle JB (1998) Mediterranean Europe as an area of endemism for small mammals rather than a source for northwards postglacial colonization. Proceedings of the Royal Society of London. Series B, Biological Sciences, 265, 1219-1226.
Blouin MS (1998) Mitochondrial DNA diversity in nematodes. Journal of Helminthology, 72, 285-289.

Blouin MS, Dame JB, Tarrant CA, Courtney CH (1992) Unusual population genetics of a parasitic nematode: mtDNA variation within and among populations. Evolution, 46, 470-476.

Blouin MS, Liu J, Berry RE (1999) Life cycle variation and the genetic structure of nematode populations. Heredity, 83, 253-259.

Blouin MS, Yowell CA, Courtney CH, Dame JB (1995) Host movement and the genetic structure of populations of parasitic nematodes. Genetics, 141, 1007-1014.

Blouin MS, Yowell CA, Courtney CH, Dame JB (1998) Substitution bias, rapid saturation, and the use of mtDNA for nematode systematics. Molecular Biology and Evolution, 15, 1719-1727.

Brown JM, Leebens-Mack JH, Thompson JN, Pellmyr O, Harrison RG (1997) Phylogeography and host association in a pollinating seed parasite Greya politella (Lepidoptera: Prodoxidae). Molecular Ecology, 6, 215-224.

Buckley TR, Simon C, Chambers GK (2001) Phylogeography of the New Zealand cicada Maoricicada campbelli based on mitochondrial DNA sequences: ancient clades associated with Cenozoic environmental change. Evolution, 55, 1395-1407.

Burban C, Petit RJ (2003) Phylogeography of maritime pine inferred with organelle markers having contrasted inheritance. Molecular Ecology, 12, 1487-1495.

Burban C, Petit RJ, Carcreff E, Jactel H (1999) Rangewide variation of the maritime pine bast scale Matsucoccus feytaudi Duc. (Homoptera: matsucoccidae) in relation to the genetic structure of its host. Molecular Ecology, 8, 1593-1602.

Campbell G, Jones CS, Lockyer AE et al. (2000) Molecular evidence supports an african affinity of the neotropical freshwater gastropod, Biomphalaria glabrata, say 1818, an intermediate host for Schistosoma mansoni. Proceedings of the Royal Society of London. Series B, Biological Sciences, 267, 2351-2358.

Clayton DH, Al-Tamimi S, Johnson KP (2003) The ecological basis of coevolutionary history. In: Tangled Trees: Phylogeny, Cospeciation, and Coevolution (ed. Page RD), pp. 310-350. University of Chicago Press, Chicago.

Clement M, Posada D, Crandall KA (2000) TCs: a computer program to estimate gene genealogies. Molecular Ecology, 9, 1657-1659.

De Meeûs T, Renaud F (2003) Parasites within the new phylogeny of eucaryotes. Trends in Parasitology, 18, 247-251.

Denver DR, Morris K, Lynch M, Vassilieva LL, Thomas WK (2000) High direct estimate of the mutation rate in the mitochondrial genome of Caenorhabditis elegans. Science, 289, 2342-2344.

Donnars O (2003) Parasites à la traîne. La Recherche, 363, 14-15.

Douady CJ, Delsuc F, Boucher Y, Doolittle WF, Douzery EJ (2003) Comparison of Bayesian and maximum likelihood bootstrap measures of phylogenetic reliability. Molecular Biology and Evolution, 20, 248-254.

Dybdahl MF, Lively CM (1996) The geography of coevolution: comparative population structures for a snail and its trematode parasite. Evolution, 50, 2264-2275.

Ehrenford FA (1954) The life cycle of Nematospiroides dubius Baylis (Nematoda: Heligmosomidae). Journal of Parasitology, 40, 480481.

Emerson BC, Oromi P, Hewitt GM (2000) Tracking colonization and diversification of insect lineages on islands: mitochondrial DNA phylogeography of Tarphius canariensis (Coleoptera: Colydiidae) on the Canary Islands. Proceedings of the Royal Society of London. Series B, Biological Sciences, 267, 2199-2205.

Felsenstein J (1985) Confidence limits on phylogenies with a molecular clock. Systematic Zoology, 34, 152-161. 
Flowerdew JR (1991) Wood mouse, Apodemus sylvaticus. In: The Handbook of British Mammals (eds Corbet GB, Harris S), 3rd edn, pp. 220-229. Blackwell Sc. Publications, Oxford, London, Edinburgh.

Frankham R, Ballou JD, Briscoe DA (2002) Introduction to Conservation Genetics. Cambridge University Press, Cambridge.

Gomez A, Carvalho GR, Lunt DH (2000) Phylogeography and regional endemism of a passively dispersing zooplankter: mitochondrial DNA variation in rotifer resting egg banks. Proceedings of the Royal Society of London. Series B, Biological Sciences, 267, 2189-2197.

Goüy de Bellocq J, Ferté H, Depaquit J, Justine JL, Tillier A, Durette-Desset MC (2001) Phylogeny of the Trichostrongylina (Nematoda) inferred from 28S rDNA sequences. Molecular Phylogenetics and Evolution, 19, 430-442.

Goüy de Bellocq J, Sara M, Casanova JC, Feliu C, Morand S (2003) A comparison of the structure of helminth communities in the woodmouse, Apodemus sylvaticus, on islands of the western Mediterranean and continental Europe. Parasitology Research, 90, 64-70.

Guindon S, Gascuel O (2003) A simple, fast, and accurate algorithm to estimate large phylogenies by maximum likelihood. Systematic Biology, 52, 696-704.

Hänfling B, Hellemans B, Volckaert FAM, Carvalho GR (2002) Late glacial history of the cold-adapted freshwater fish Cottus gobio, revealed by microsatellites. Molecular Ecology, 11, 17171729 .

Hawdon JM, Li T, Zhan B, Blouin MS (2001) Genetic structure of populations of the human hookworm, Necator americanus, in China. Molecular Ecology, 10, 1433-1437.

Hewitt G (1999) Post-glacial recolonisation of European biota. Biological Journal of the Linnean Society, 68, 87-112.

Hewitt G (2000) The genetic legacy of the Quaternary ice ages. Nature, 405, 907-913.

Huelsenbeck JP, Ronquist F, Nielsen R, Bollback JP (2001) Bayesian inference of phylogeny and its impact on evolutionary biology. Science, 294, 2310-2314.

Johnson KP, Williams BL, Drown DM, Adams RJ, Clayton DH (2002) The population genetics of host specificity: genetic differentiation in dove lice (Insecta: Phthiraptera). Molecular Ecology, 11, 25-38.

Jones RL, Keen DH (1993) Pleistocene Environments in the British Isles, p. 346. Chapman \& Hall Publishers, London.

Koskinen MT, Ranta E, Piironen J et al. (2000) Genetic lineages and postglacial colonization of grayling (Thymallus thymallus, Salmonidae) in Europe, as revealed by mitochondrial DNA analyses. Molecular Ecology, 9, 1609-1624.

Luikart G, Gielly L, Excoffier L, Vigne JD, Bouvet J, Taberlet P (2001) Multiple maternal origins and weak phylogeographic structure in domestic goats. Proceedings of the National Academy of Sciences of the United States of America, 98, 5927-5932.

Mavarez J, Pointier J-P, David P, Delay B, Jarne P (2002) Genetic differentiation, dispersal and mating system in the schistosometransmitting freshwater snail Biomphalaria glabrata. Heredity, 89, 258-265.

McCoy KD, Boulinier T, Tirard C, Michalakis Y (2003) Hostdependent genetic structure of parasite populations: differential dispersal of seabird tick host races. Evolution, 57, 288-296.

Michaux JR, Libois R, Ramalhinho MG, Maurois C (1998) On the mtDNA restriction patterns variation of the Iberian wood mouse (Apodemus sylvaticus). Comparison with other west mediterranean populations. Hereditas, 129, 187-194.
Michaux JR, Magnanou E, Paradis E, Nieberding C, Libois R (2003) Mitochondrial phylogeography of the wood mouse (Apodemus sylvaticus) in the western Palearctic region. Molecular Ecology, 12, 685-697.

Michaux J, Pasquier L (1974) Dynamique des populations de mulots (Rodentia, Apodemus) en Europe durant le Quaternaire. Premières Données Bulletin Société Géologique France, 7, 431-439.

Mulvey M, Aho JM, Lydeard C (1991) Comparative population genetic structure of a parasite (Fascioloides magna) and its definitive host. Evolution, 45, 1628-1640.

Nadler SA (1990) Molecular approaches to studying helminth population genetics and phylogeny. International Journal of Parasitology, 20, 11-29.

Nadler SA (1995) Microevolution and the genetic structure of parasite populations. Journal of Parasitology, 81, 395-403.

Nieberding C, Morand S, Libois R, Michaux JR (2004) A parasite reveals cryptic phylogeographic history of its host. Proceedings of the Royal Society of London. Series B, Biological Sciences, 271, 2559-2568.

Page RD, Lee PL, Becher SA, Griffiths R, Clayton DH (1998) A different tempo of mitochondrial DNA evolution in birds and their parasitic lice. Molecular Phylogenetics and Evolution, 9, 276-293.

Pellmyr O, Leebens-Mack J, Thompson JN (1998) Herbivores and molecular clocks as tools in plant biogeography. Biological Journal of the Linnean Society, 63, 367-378.

Pfenninger M, Posada D, Magnin F (2003) Evidence for survival of Pleistocene climatic changes in northern refugia by the land snail Trochoidea geyeri (Soos 1926) (Helicellinae, Stylommatophora). BMC Evolutionary Biology, 3, 1-8.

Philippe H (1993) MUST, a computer package for management utilities for sequences and trees. Nucleic Acids Research, 21, 5264-5272.

Posada D, Crandall KA (1998) Modeltest: testing the model of DNA substitution. BioInformatics, 14, 817-818.

Queney G, Ferrand N, Weiss S, Mougel F, Monnerot M (2001) Stationary distributions of microsatellite loci between divergent population groups of the European rabbit (Oryctolagus cuniculus). Molecular Biology and Evolution, 18, 2169-2178.

Rozas J, Rozas R (1997) DNASP (version 2.0): a novel software package for extensive molecular population genetic analysis. Computer Application in the Biosciences, 13, 307-311.

Schneider S, Roessli D, Excoffier L (2000) ARLEQUIN, version 2.0: A Software for Population Genetic Data Analysis. Genetics and Biometry Laboratory, University of Geneva, Geneva, Switzerland.

Schultheis AS, Weigt LA, Hendricks AC (2002) Gene flow, dispersal, and nested clade analysis among populations of the stonefly Peltoperla tarteri in the southern Appalachians. Molecular Ecology, 11, 317-327.

Sinclair WT, Moramn JD, Ennos RA (1999) The postglacial history of Scots pine (Pinus sylvestris L.) in western Europe: evidence from mitochondrial DNA variation. Molecular Ecology, 8, 83-88.

Stewart JR (2003) Response to comment on 'Buffered tree changes in a Quaternary refugium: evolutionary implications'. Science, 299, 825a.

Stewart JR, Lister AM (2001) Cryptic northern refugia and the origins of modern biota. Trends in Ecology and Evolution, 16, 608-613.

Swofford DL (1998) PAUP*: Phylogenetic Analysis Using Parsimony (and Other Methods), Version 4.0. Sinauer Associates, Sunderland, Massachusetts.

Taberlet P, Fumagalli L, Wust-Saucy AG, Cosson JF (1998) Comparative phylogeography and postglacial colonization routes in Europe. Molecular Ecology, 7, 453-764. 
Thaler L (1973) Nanisme et gigantisme insulaire. La Recherche, 37, 741-750.

Thomas F, Verneau O, De Meeûs T, Renaud F (1996) Parasites as to host evolutionary prints: insights into host evolution from parasitological data. International Journal of Parasitology, 26, 677-686.

Trewick SA, Wallis GP (2001) Bridging the 'beech-gap': New Zealand invertebrate phylogeography implicates Pleistocene glaciation and Pliocene isolation. Evolution, 55, 2170-2180.

Tyler T (2002) Geographic distribution of allozyme variation in relation to post-glacial history in Carex digitata, a widespread European woodland sedge. Journal of Biogeography, 29, 919930.

Tzedakis PC (2003) Response to comment on 'Buffered tree changes in a Quaternary refugium: evolutionary implications'. Science, 299, 825b.

Vandewoestijne S, Baguette M, Brakefield PM, Saccheri IJ (2004) Phylogeography of Aglais urticae (Lepidoptera) based on DNA sequences of the mitochondrial COI gene and control region. Molecular Phylogenetics and Evolution, 31, 630-646.

Viney ME (1998) Nematode population genetics. Journal of Helminthology, 72, 281-283.
Wickström LM, Haukisalmi V, Varis S, Hantula J, Fedorov VB, Henttonen H (2003) Phylogeography of the circumpolar Paranoplocephala arctica species complex (Cestoda: Anoplocephalidae) parasitizing collared lemmings (Dicrostonyx spp.). Molecular Ecology, 12, 3359-3371.

Yalden DW (1982) When did the mammal fauna of the British Isles arrive ? Mammal Review, 12, 1-57.

This work represents part of Caroline Nieberding's PhD which deals with the comparison of the European phylogeographic patterns of the nematode Heligmosomoides polygyrus and the rodent Apodemus sylvaticus. Roland Libois is Professor associate at Ulg and has notably been conducting ecological research on European rodents for nearly three decades. Christophe Douady has contributed to the phylogenetic reconstructions and to the structural organization of the manuscript. Serge Morand is interested in host-parasite co-evolution and has contributed throughout this PhD program. Johan Michaux studies the phylogeographic pattern of various common and threatened European mammal species. 